\title{
The Effects of Siblings Composition on the Children's Intellectual Performance in Indonesia
}

\author{
Gisty Ajeng Septami \\ Department of Economics \\ University of Indonesia \\ Depok, West Java \\ agiseptami@gmail.com
}

\author{
I Dewa Gede Karma Wisana \\ Demographic Institute \\ Faculty of Economics and Business, University of Indonesia \\ Depok, West Java \\ dewa_wisana@yahoo.com
}

\begin{abstract}
Number of children and the perfect time to raise children is one of paramount decisions that a household encounters. This rationale appeared since parents recently realized that the number of children they have, the birth order and/or a certain birth-interval between children does matter in influencing the outcome of children, including the children's intelligence. Although the impacts of family structure on children's outcome in Indonesia have been widely examined; the literatures exploring birth order among siblings, along with the impacts of birth interval on child's wellbeing are so far hardly found. Utilizing the large-scale outgoing longitudinal data, Indonesia Family Life Survey (IFLS) year 2007, this study attempts to find whether birth order and birth spacing affect the older sibling's intelligence at the age of 7-14 years old. The OLS results suggest that birth order adversely affects the child's intellectual performance. However, such effect becomes negligible and insignificant when there is a longer birth gap between children. In addition, those cognitive-endowment-related factors will be gratuitous if there is no cognitive development process at home. From the perspective of family planning program, the findings propose a need for policy design persuading longer inter-pregnancy gap for the sake of intelligence outcome.
\end{abstract}

Keywords-Birth Order, Birth Spacing, Intelligence Outcome, Indonesia Family Life Survey (IFLS), Indonesia.

\section{INTRODUCTION}

Numerous empirical studies have explored on how family structure affects children's quality. Several previous literatures focused primarily on the inverse relationship between an individual's outcome and the number of his or her siblings. A study stated that as the number of sibling increases, the parents' time and material resources for each child diminish. This diminution is translated into a burden of each child outcome [1]. Children from larger families generally have diminished outcomes, for instance, lower educational achievement, slower achievement growth, weaker health performance, worse exercise outcomes, and tend to engage in risky behavior [2] [3] [4] [5] [6] [7].

Beyond the trade-off between child quantity and quality, a recent argument considered that siblings are impossible to receive equal number of resources committed by parents to their children's investments. It advances the studies about the effects of family structures by taking birth order variable into an amended model. Until now, the effects of birth order on children's outcome are still a puzzle; however, majority suggested a negative association between them- the higher the birth rank order, the lower the child's outcomes. As a result, the earlier-born children tend to have higher educational attainment, stronger health performance, and unlikely to be exposed by mortality risk [8] [9] [10] [11].

Even though the hypotheses of birth order would give new understanding of the effects of family structure, the mechanisms of the effects could be mitigated by spacing [12]. Furthermore, unlike birth order, spacing is a matter over which parents might control [13]. However, several social science literatures examined birth-spacing effects. The prior studies mostly focused on medical and psychological fields which discussed about the very early outcomes instead of the role of spacing on later children quality, such as intelligence. Some evidences proved that the shorter gaps between siblings risk highly on the adverse perinatal and maternal outcomes and the rivalry atmosphere among children to grab some sameresources [14] [15].

According to the findings above, it can be concluded that children's outcomes can be influenced by three family compositions: number of children, birth order and birth spacing. Nonetheless, many developing countries only promoted the important of the number of children and neglected the other two in the family planning programs. For instance, the early message of the family planning campaign in Bangladesh sounded "a small family is a happy family". Then, Singapore promoted "two is enough" or "stop at two" and South Korea suggested "small and prosperous family". Furthermore, the Government of Indonesia (GoI) is presently only prioritizing the family size control. The agenda set up some information and counseling campaign conveying to be better with only two children at home, but the rest family structures have never been taken into account. However, this regulation may have an unintended consequence (either positive or negative) if spacing affects the children outcomes.

Although the impacts of family structure on children's outcome in Indonesia have been widely examined, the literatures exploring the impacts of birth interval on child's wellbeing are non-existence so far. Therefore, this study attempts to observe the effects of birth order and birth spacing on one important later-life outcome: children's intelligence, by 
utilizing the on-going longitudinal survey data-Indonesia Family Life Survey (IFLS). This study focused on children aged 7-14 years old from a family with at least two live births and observed the spacing in months between their births. This category of children was selected in order to observe the empirical evidence at the time when siblings were growing together under the nurture of their parents. Moreover, the child's intelligence was gauged using the cognitive test score documented in 2007.

\section{LITERATURE REVIEW}

\section{A. The Quantity-Quality Model}

In 1973, Becker and Lewis explored the interactions between quantity and quality of children. They started to value the trade-off by using the shadow price (marginal cost) of children. The shadow price of children's quality (i.e., the cost of a unit increase in quality, holding number constant) went up as the quantity of children increased. In the same way, the shadow price of children's quantity (i.e., the cost of an additional child, holding their quality constant) was greater as the quality of children was higher.

The prices correlations describe the interaction between quantity and quality of children. It concludes that the cost spent on every additional child in a family (with the quality remains constant) will be higher than on every additional quality (with the quantity remains constant). Consequently, the economic interpretation is an increase in quality is more expensive if there are more children, because the increase must be applied to more units; similarly, an increase in quantity is more expensive if the children are of higher quality, because higherquality children cost more [16].

\section{B. Beyond the Trade-off: The Confluence Model}

Beyond the trade-off between children's quantity and quality, a study offered a theory of family configuration effects to intelligence, which is called as the Confluence Model [17]. Basically, this explanation suggests the intellectual growth rate of every member within a family as a function of the intellectual environment in the family $(\alpha)$ at the time $t$. Intellectual environment is defined as the average of the absolute intellectual levels of its members [12], and will change continuously as the family member alteration.

The following examples illustrate, in a simplified form, the reliance of the intellectual advancement on the altered family configuration. Considering the absolute intellectual levels of the parents are 100 arbitrary units each, and a value near zero for the new born, then the intellectual environment in a given family at the birth of the first child is $(100+100+0) / 3=67$. A while later, suppose the second child is born when the absolute intellectual level of the older sibling attains 20, then the younger enters into an intellectual environment of $(100+100+$ $20+0) / 4=55$. If a third child is born when the oldest reaches an intellectual level of 40 and the second child is now at 10, the family intellectual environment will then be reduced to 50 . In general, if such a pattern continues, it should be clear that the ensuing children will be born into a subjacent environment. This instance also tells us that the intellectual environment is lessened with birth order.
However, the effect of birth order is not an important variable since its effect is interceded by the birth interval between siblings. Being assumed that if the second child is not born until the oldest reaches an intellectual level of 50 , for instance, then the newborn enters an environment of $(100+$ $100+60+0) / 4=65$, which is such a more beneficial environment than the previous example. Hence, giving adequate time for the earlier born to mature by enough gaps between siblings, the birth order effect can be attenuated. Therefore, this analysis leads to the conclusion that there are two major determinants of intellectual growth, both imbedded in the individual's intellectual development: the spacing between children and the family size [18].

\section{DATA AND METHODOLOGY}

\section{A. Data}

This study analyzed the large-scale ongoing longitudinal household survey data in Indonesia, the Indonesia Family Life Survey (IFLS) in wave of 2007. IFLS was conducted on individual, household, community, and facility level and had been done five times in Indonesia. In the analysis, this study briefly focused on children aged 7-14 years old from a family with at least two live births in IFLS4. This category of children was selected in order to observe the empirical evidence at the time when siblings were growing together under the nurture of their parents. Moreover, the age limitation is aimed to know the cognitive skills of sample by employing the cognitive information in book EK1 IFLS4; so that, the effects of birth interval on children's intelligence can be clearly determined. In addition, the only child and twins in a family are excluded to minimize the bias estimation.

Table 1. Summary of Variables

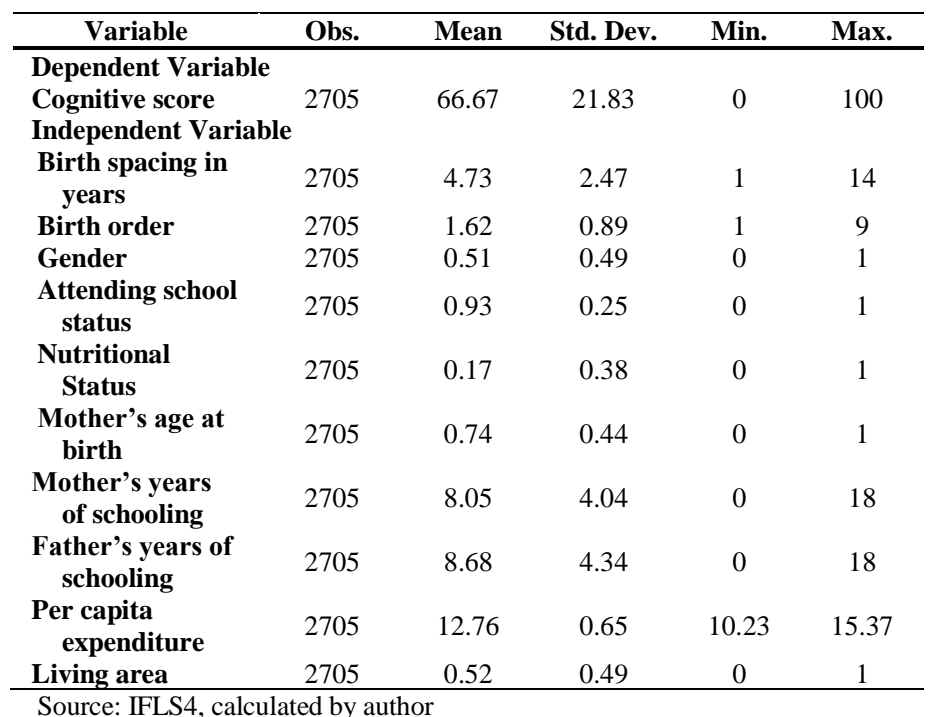

The unit of analysis in this study is the biological child of the head of a household with the mother aged 15-49 years old. This limitation complies with the previous study about the tradeoff between quantity and quality of children [11] in order to minimize the bias on defining the number of children. This 
study matched the children to their parents and household characteristics. Based on the selection criteria, it was found 2,705 older siblings who became the subjects in this study. The variables used in this study are divided into two main variables (birth order and birth spacing) and three other explanatory variables which are individual characteristic, parents' characteristic, and household characteristic.

\section{B. Methodology}

This study employed the research model initiated by Buckles and Munnich [19]. They analyzed separately for older and younger children. They began their study by estimating the effects using OLS. The primary result showed that longer spacing between siblings is associated with higher test scores, especially for older siblings. However, if spacing between siblings is correlated with unobservable characteristics of the mother or children, then the OLS estimation may be biased .

However, this study did not fully employ the Buckles and Munnich research model; Instead, this study analyzed only the birth spacing effects on the older siblings. This is due to the difficulty in searching some explanations about the effects on younger siblings. A model modification was done referred to the data availability in IFLS4 by eliminating and adding some variables. The model to be estimated is:

The Indonesia Family Life Survey (IFLS) 2007 which is the large-scale ongoing longitudinal household survey data conducted on individuals was analyzed:

$$
\text { Score }=\mathrm{f}(\mathrm{BO}, \mathrm{BS}, \mathrm{CCh}, \mathrm{PCh}, \mathrm{FCh})
$$

$$
\begin{aligned}
\text { Score = } & \text { The IQ score } \\
\mathrm{BO}= & \text { Birth order } \\
\mathrm{BS}= & \begin{aligned}
\mathrm{B} \text { irth spacing with the closest younger sibling in } \\
\text { months }
\end{aligned} \\
\mathrm{CCh}= & \text { A set of characteristics specific to child, including } \\
& \text { gender, attending school status, and nutritional } \\
& \text { status } \\
= & \text { A set of parents characteristics, including } \\
& \text { mother's age at birth, mother's years of } \\
& \text { schooling, and father's years of schooling } \\
= & \text { A set of household characteristics, including per } \\
& \text { capita expenditure (in log) and living area }
\end{aligned}
$$

\section{FINDINGS}

Having merged and selected, it was found 2705 children as the observation target. Table 1 summarizes all variables used in this study. Cognitive score is a proxy of children's quality used as the dependent variable; meanwhile, explanatory variables are categorized into three groups; children characteristic, parents' characteristic, and household characteristic.

This study found an inverse correlation between the birth order and children's cognitive performance. The result shows a negative relationship between birth order and cognitive score; the child with higher birth order has lower mean of cognitive score. It proved the existence of trade-off between quantity and quality of children in Indonesia. It was assumed that the birth order rank of children as a proxy of the number of children born in a household. Then, the higher the birth order rank of children which means the larger the number of children born in a household decreases the intellectual performance of the children.

At the same time, this study revealed that the sample of this study have enough intervals, with about 75 percent of children were born after an interval of 36 months and a median of 56 months. The result shows a relationship between birth spacing and cognitive score. Although the differences cannot be clearly determined from the figure, but it can be seen that children whose age intervals are more than 36 months to their closest younger siblings tend to have higher cognitive score, with the mean of cognitive score is 66.96. Meanwhile, those who have less than 36 months birth spacing to their closest younger siblings have lower mean of cognitive score, 65.58. The vertical line in both figure is the cut-off of cognitive score category - whether having higher or lower cognitive ability.

Furthermore, this study conducted four specific estimations to check the consistency and robustness of the results. The estimated models proposed are as follows:

(1) Score $=f($ Birth order).

(2) Score $=f($ Birth spacing)

(3) Score $=f($ Birth order,Birth spacing)

(4) Score $=\mathrm{f}(\mathrm{BO}, \mathrm{BS}$, Children Characteristics, Parents'

Characteristics, Household' s Characteristics)

In specification (1) and specification (2), respectively, this study observed the effects of birth order and birth spacing on the older sibling outcomes, without any controls. In specification (3), the study observed the effects of birth order with the birth spacing variable included. At the end, specification (4) included all the independent variables into the estimation.

In the first column, it can be seen that without any control, the correlation is negative and statistically significant. It can be said that within each family, the cognitive scores of children decline with birth order. This finding revealed that the birth order affects the resources allocation process devoted by parents. However, the negative effect of birth order can be mediated entirely by the age spacing between siblings [12]. A child who is long-spaced from their siblings is likely to be transferred with more resources; and this may, to some extent, reduce the negative effects of birth order.

The specification (3) shows that the effects of birth order became negligible when the birth spacing variable was included. Moreover, in constrast to birth order variable, the coefficient of birth spacing remained indifferent when some controls were added in the specification (4); while the birth order coefficient experienced a dramatic declining. To some extent, it can be said that the effects of birth spacing significantly more influence the children's outcomes in Indonesia than the effects of birth order. 
Table 2. Regression Result

Dependent Variable: Cognitive Score

\begin{tabular}{|c|c|c|c|c|}
\hline $\begin{array}{c}\text { Independent } \\
\text { Variables }\end{array}$ & Model 1 & Model 2 & Model 3 & $\begin{array}{c}\text { Model } \\
4\end{array}$ \\
\hline Birth Order & $\begin{array}{l}-2.152 * * * \\
(0.503)\end{array}$ & & $\begin{array}{c}-2.089 * * * \\
(0.504)\end{array}$ & $\begin{array}{l}-0.498 \\
(0.466)\end{array}$ \\
\hline \multirow[t]{2}{*}{ Birth spacing } & & $0.059 * * *$ & $0.058 * * *$ & $\begin{array}{l}0.057 * \\
* *\end{array}$ \\
\hline & & $(0.013)$ & $(0.013)$ & (0.013) \\
\hline Sex & & & & $\begin{array}{l}-0.860 \\
(0.796)\end{array}$ \\
\hline \multirow[t]{2}{*}{$\begin{array}{l}\text { Attending school } \\
\text { status }\end{array}$} & & & & $\begin{array}{l}10.74 * \\
* *\end{array}$ \\
\hline & & & & (2.175) \\
\hline \multirow[t]{2}{*}{$\begin{array}{l}\text { Body Mass Index } \\
\text { (BMI) }\end{array}$} & & & & $\begin{array}{c}7.872 * \\
* *\end{array}$ \\
\hline & & & & $(0.956)$ \\
\hline Maternal Age & & & & $\begin{array}{l}1.722 * \\
(0.958)\end{array}$ \\
\hline \multirow[t]{2}{*}{$\begin{array}{l}\text { Mother's years of } \\
\text { education }\end{array}$} & & & & $\begin{array}{l}0.507 * \\
* *\end{array}$ \\
\hline & & & & $(0.138)$ \\
\hline \multirow[t]{2}{*}{$\begin{array}{l}\text { Father's years of } \\
\text { education }\end{array}$} & & & & $\begin{array}{c}0.286^{*} \\
*\end{array}$ \\
\hline & & & & (0.129) \\
\hline \multirow[t]{2}{*}{$\begin{array}{l}\text { Log per capita } \\
\text { expenditure }\end{array}$} & & & & $\begin{array}{l}3.552 * \\
* *\end{array}$ \\
\hline & & & & (0.699) \\
\hline Living area & & & & $\begin{array}{l}1.242 \\
(0.843)\end{array}$ \\
\hline Constant & $\begin{array}{c}70.15 * * * \\
(0.895)\end{array}$ & $\begin{array}{c}63.05 * * * \\
(0.938)\end{array}$ & $\begin{array}{c}66.55 * * * \\
(1.259)\end{array}$ & $\begin{array}{l}-0.659 \\
(8.746)\end{array}$ \\
\hline Obs & 2705 & 2705 & 2705 & 2705 \\
\hline Prob $>F$ & 0.0000 & 0.0000 & 0.0000 & 0.0000 \\
\hline R-Squared & 0.0079 & 0.0066 & 0.0141 & 0.1097 \\
\hline
\end{tabular}

Notes: robust standard error. Level of significance $* * * 1 \%, * * 5 \%$, and $* 10 \%$ Source: IFLS4, processed.

Several biological and behavioral mechanisms are often cited to explain the effects of birth spacing on the children's outcomes [3] [13]. The explanation can be divided into four categories: sibling rivalry due to the parents constraint, household environment, maternal depletion syndrome, and cultural effects.

Firstly, the basic idea behind the constraint scheme is that parents have fixed time and financial endowment over the life cycle, making it hard to equalize the resources over their children [3]. Willis and Parish (1993) noted that the children of lower birth order hold a privileged position from being a child in smaller families [20]. This may favor them over laterborns as they might receive greater attention than the subsequent children who have to compete for parental endowment.

Nevertheless, the later-borns older siblings do not need to worry about their suboptimum outcomes as long as they are long-spaced to their younger siblings. It is because a longer spacing creates more "breathing room" for both children and their parents. The larger spacing would upgrade the quality of parent-adolescent relationship [21]. Additionally, [20] and [21] suggested that the curse of birth order can be turned into a premium when spacing is longer. It was assayed that first children averagely receive about 3,000 more hours of parental time than secon-born children aged 4-13 (2008), and this investment difference increases about $25 \%$ each year of spacing (2010) [22] [23].

Secondly, the Confluence Model explaines the negative effects of birth order on children's outcome through an intellectual test performance in the household environment. The intellectual environment is conceptualized as an average of all members' absolute contribution, then it changes progressively as the children increase [12]. In general, if the pattern continues, it should be clear that the ensuing children will be born into a subjacent environme-nt.

However, [12] said that larger intervals between older siblings and their younger siblings might balance the regressing effects of late birth order, even in extreme cases might reverse them. The older siblings would have lived a more favorable intellectual environment for a longer time before their successive sibling entered. Moreover, if the samples (which acted as older siblings) had other older siblings, wider age gaps between them would be beneficial to the samples. The samples would enter a progressively better environment and the average intellectual levels would escalate with family size [12].

In the third scheme, biological factors may also induce a negative effect of birth order. One possible example is the maternal nutritional degradation. The later-born children originally have older mothers. The older mothers delivered lower birth-weight children which is correlated with the ability or access to resources; then children of higher birth order may get worse resources [24].

On the other hand, several medical literatures stated that the long inter-pregnancy intervals may overcome the effects of birth on infant's outcomes, such as infant mortality, still birth, preterm delivery, and low birth weight [13]. The child born after a long-spacing with his/her older sibling could be advantaged with sufficient fetal nutrition [15]. If inter-sibling interval affects infant health or child development, this may be related to spacing and other outcomes like cognitive score [13].

Lastly, the cultural factors may urge the negative effects of birth order. Older children tend to have an opportunity to be the intellectual resources. This status leads the older children to have a responsibility to assist their younger siblings. Their assisting by teaching or explaining something would be seen from other's reactions; whether the explanation was wellunderstood, and was prompted to dig deeper and improved the explanation. Consequently, his or her own understanding of the matter would be improved as well. [12].

However, in order to assist the younger siblings, older siblings tend to leave home eventually to provide new resources if their age gaps are close. By losing their opportunity to learn and get more knowledge at school and in training their younger siblings, their cognitive development will be diminished. Hence, a long birth spacing between siblings is needed.

Besides doing a regression in a linear version, this study also did a regression with quadratic functional form. It suggests that the relationship between birth spacing and cognitive score might be non-linear and the level of spacing optimizing the cognitive scores is predicted around 4 years. Older siblings 
who were born 4 years earlier than their younger siblings tend to have higher cognitive performance.

\section{CONCLUSION}

Although the impacts of family structure on children's outcome in Indonesia have been widely examined, the literatures exploring birth order among siblings, along with the impacts of birth interval on child's wellbeing are hardly found so far. Hence, this study attempts to observe the effects of birth order and birth spacing on one important later-life outcome: children's intelligence, by utilizing the on-going longitudinal survey data-Indonesia Family Life Survey (IFLS) year 2007. This study focused on children aged 7-14 years old from a family with at least two live births and observed the spacing in months between their births.

By employing OLS regression technique, this study found statistically a significant negative effect of birth order on children's cognitive score. This finding revealed that siblings are improbable to receive equal shares of the resources committed by parents to their children's investments. However, the negative effects of birth order can be mediated entirely by the age spacing between siblings. A child who is long-spaced from their siblings is likely to be transferred with more resources, and this [18]may reduce the negative effects of birth order.

As a matter of public policy, these findings suggest a breaktrough in family planning programs that encourage longer inter-pregnancy intervals for better children's cognitive ability. In addition, it is important to promote equal accesses to education, health facility and information for children. However, there are few issues that were addressed yet not attempted further in this study as they became the limitation of this study. Further research is expected to upgrade the regression technique from OLS to 2 SLS since there is a heterogeneity problem from birth spacing variable that makes the result of this study is either underestimated or overestimated. Another issue is to conduct series of robustness checking by utilizing other outcomes, such as academic achievement, health outcome, educational attainment and the children behaviors.

\section{References}

[1] D. M. Heer, "Effects of Sibling Number on Child Outcome," Annual Review of Sociology, vol. 11, no. 1, pp. 27-47, August 1985.

[2] Arleen Leibowitz, "1974," The American Economic Review, vol. 64, no. 2, pp. 243-250, May 1974.

[3] Mette, and Claus C. Pörtner Ejrnæs, "Birth order and the intrahousehold allocation of time and education," Birth, vol. 26, no. 4, March 2006.

[4] Daniel Kessler, "Birth order, family size, and achievement: Family structure and wage determination," Journal of Labor Economics, vol. 9, no. 4, pp. 413-426, October 1991.

[5] Eric. A. Hanushek, "The trade-off between child quantity and quality," Journal of political economy, vol. 100, no. 1, pp. 84-117, Februari 1992.
[6] Hongbin, Junsen Zhang, and Yi Zhu Li, "The quantityquality trade-off of children in a developing country: Identification using Chinese twins," Demography, vol. 45, no. 1, pp. 223-43, Februari 2008.

[7] Olivier Deschênes, "Estimating the effects of family background on the return to schooling," Journal of Business \& Economic Statistics, vol. 25, no. 3, pp. 265277, July 2007.

[8] Nancy Birdsall, "Birth order effects and time allocation," Research in population economics, vol. 7, pp. 191-213, 1991.

[9] Bitte Modin, "Birth order and mortality: a life-long follow-up of 14,200 boys and girls born in early 20th century Sweden," Social science \& medicine, vol. 54, no. 7, pp. 1051-1064, April 2002.

[10] Kieron, and Martin Kolk Barclay, "Birth order and mortality: A population-based cohort study," Demography, vol. 52, no. 2, pp. 613-639, April 2015.

[11] Sandra E., Paul J. Devereux, and Kjell G. Salvanes Black, "The more the merrier? The effect of family size and birth order on children's education," The Quarterly Journal of Economics, vol. 120, no. 2, pp. 669-700, May 2005.

[12] Robert B Zajonc, "Family configuration and intelligence," Science, vol. 192, no. 4236, pp. 227-236, April 1976.

[13] Kasey S., and Elizabeth L. Munnich Buckles, "Birth spacing and sibling outcomes," Journal of Human Resources, vol. 47, no. 3, pp. 613-642, July 2012.

[14] Wyndol, and Duane Buhrmester Furman, "Children's perceptions of the personal relationships in their social networks," Developmental psychology, vol. 21, no. 6, p. 1016, November 1985.

[15] Agustin, Anyeli Rosas-Bermúdez, and Ana Cecilia Kafury-Goeta Conde-Agudelo, "Birth spacing and risk of adverse perinatal outcomes: a meta-analysis," Jama, vol. 295, no. 15, pp. 1809-1823, April 2006.

[16] Gary S., and H. Gregg Lewis Becker, "On the Interaction between the Quantity and Quality of Children," Journal of political Economy, vol. 81, no. 2, pp. S279-S288, March 1973.

[17] Robert B., and Gregory B. Markus Zajonc, "Birth order and intellectual development," Psychological review, vol. 82, no. 1, p. 74, January 1975.

[18] and Gregory B. Markus Zajonc Robert B., "Birth Order and Intellectual Development," Psychological Review, vol. 82, no. 1, p. 85, January 1975.

[19] K. S. and Munnich, E. L. Buckles, "Birth Spacing and Sibling Outcomes," Journal of Human Resources, vol. 47, no. 3, 2012.

[20] William L., and Willis, Robert J. Parish, "Daughters, education, and family budgets Taiwan experiences," Journal of Human Resources, pp. 863-98, October 1993. 
[21] Jeannie S Kidwell, "Perceived Parent-Adolescent Relationships," Journal of Marriage and the Family , May 1981.

[22] Joseph Price, "Parent-Child Quality Time Does Birth Order Matter?," Journal of Human Resources, vol. 43, no. 1, pp. 240-265, January 2008.

[23] Joseph Price, "The effects of parental time investments: Evidence from natural within-family variation.," Unpublished manuscript, Brigham Young University, 2010.
[24] Alison L., and Hiau Joo Kee Booth, "Birth order matters: the effect of family size and birth order on educational attainment," Journal of Population Economics, vol. 22, no. 2, pp. 367-97, April 2009. 